\title{
Surface-Aerosol Stability and Pathogenicity of Diverse Middle East Respiratory Syndrome Coronavirus Strains, 2012-2018
}

\author{
Neeltje van Doremalen, ${ }^{1}$ Michael Letko, ${ }^{1}$ Robert J. Fischer, Trenton Bushmaker, \\ Jonathan Schulz, Claude K. Yinda, Stephanie N. Seifert, Nam Joong Kim, Maged G. Hemida, \\ Ghazi Kayali, Wan Beom Park, Ranawaka A.P.M. Perera, Azaibi Tamin, Natalie J. Thornburg, \\ Suxiang Tong, Krista Queen, Maria D. van Kerkhove, Young Ki Choi, Myoung-don Oh, \\ Abdullah M. Assiri, Malik Peiris, Susan I. Gerber, Vincent J. Munster
}

Middle East respiratory syndrome coronavirus (MERSCoV) infects humans and dromedary camels and is responsible for an ongoing outbreak of severe respiratory illness in humans in the Middle East. Although some mutations found in camel-derived MERS-CoV strains have been characterized, most natural variation found across MERS-CoV isolates remains unstudied. We report on the environmental stability, replication kinetics, and pathogenicity of several diverse isolates of MERS-CoV, as well as isolates of severe acute respiratory syndrome coronavirus 2 , to serve as a basis of comparison with other stability studies. Although most MERS-CoV isolates had similar stability and pathogenicity in our experiments, the camel-derived isolate $\mathrm{C} / \mathrm{KSA} / 13$ had reduced surface stability, and another camel isolate, $\mathrm{C} /$ $B F / 15$, had reduced pathogenicity in a small animal model. These results suggest that although betacoronaviruses might have similar environmental stability profiles, individual variation can influence this phenotype, underscoring the need for continual global viral surveillance.

Author affiliations: National Institutes of Health, Hamilton, Montana, USA (N. van Doremalen, M. Letko, R.J. Fischer, T. Bushmaker,

J. Schulz, C.K. Yinda, S.N. Seifert, V.J. Munster); Washington State University, Pullman, Washington, USA (M. Leitko, S.N. Seifert);

Seoul National University College of Medicine, Seoul, South Korea (N.J. Kim, W.B. Park, M.-d. Oh); King Faisal University, Al-Hasa,

Saudi Arabia (M.G. Hemida); Kafrelsheikh University, Kafrelsheikh, Egypt (M.G. Hemida); University of Texas Health Sciences Center, Houston, Texas, USA (G. Kayali); University of Hong Kong, Hong Kong, China (R.A.P.M. Perera, M. Peiris); Centers for Disease Control and Prevention, Atlanta, Georgia, USA (A. Tamin,

N.J. Thornburg, S. Tong, K. Queen, S.I. Gerber); World Health

Organization, Geneva, Switzerland (M.D. van Kerkhove); Chungbuk National University, Cheongju City, South Korea (Y.K. Choi);

Ministry of Health, Riyadh, Saudi Arabia (A.M. Assiri)
$\mathrm{M}$ iddle East respiratory syndrome coronavirus (MERS-CoV) was detected during 2012 and continues to cause outbreaks as a result of frequent spillover from dromedary camels to humans. Human infection with MERS-CoV has a mortality rate of $\approx 35 \%$, and the virus has spread to 27 countries (1). Approximately $41 \%$ of human MERS-CoV infections in Saudi Arabia are primary, resulting from direct camel-to-human transmission (2). To date, MERS-CoV has been detected in camels in Burkina Faso, Egypt, Ethiopia, Jordan, Kenya, Morocco, Nigeria, Saudi Arabia, Senegal, Sudan, Tunisia, and Uganda (3-11).

Human-to-human transmission of MERS-CoV primarily occurs in hospital settings and within households (12). Epidemiologic studies have mapped indirect patient contact within hospitals, providing evidence for aerosol-mediated and hospital-workermediated spread (13-16). The largest outbreak of infection with MERS-CoV outside the Middle East occurred when 1 traveler from the Middle East brought MERS-CoV to South Korea, resulting in 185 subsequent infections (17).

Coronaviruses have large, nonsegmented, positive-sense RNA genomes. The $1 \%$ nucleotide sequence variation reported between various MERS-CoV isolates collected in the Middle East and North Africa is equivalent to $300 \mathrm{nt}$ changes in the $30-\mathrm{kB}$ viral genome (18). Many of these changes are nonsynonymous and distributed throughout the viral genome. Even single amino acid changes in MERS-CoV can alter viral replication (19), and deletions in MERS-CoV have been shown to attenuate

${ }^{1}$ These authors contributed equally to this article. 
pathology in an animal model (18). These findings underscore the need for characterizing how MERS$\mathrm{CoV}$ genetic variation alters viral replication, pathogenicity, and stability.

We tested a broad panel of viral isolates collected from humans and camels, representing every major geographic region that has had MERS-CoV outbreaks and spanning from early to contemporary outbreaks. Because MERS-CoV spreads within households and hospitals, we characterized viral phenotypes with immediate implications for public health. We focused on environmental stability in aerosols as well as surface stability on common materials found in hospitals, replication kinetics in immortalized human cell lines and primary human airway epithelial cultures, and pathogenicity in a transgenic mouse model our laboratory developed to test vaccine efficacy (20). For environmental stability studies, we included severe acute respiratory syndrome coronavirus 2 (SARS-CoV-2) to enable better comparison of these findings with those of previously published stability studies (21).

\section{Methods}

\section{Ethics}

Animal experiment approval was obtained by the Institutional Animal Care and Use Committee at Rocky Mountain Laboratories, National Institutes of Health (Hamilton, MT, USA). All animal experiments were executed in an Association for Assessment and Accreditation of Laboratory Animal Care-approved facility, following the guidelines in National Institutes of Health Guide for the Care and Use of Laboratory Animals, Animal Welfare Act, US Department of Agriculture, and United States Public Health Service Policy on Humane Care and Use of Laboratory Animals. The Institutional Biosafety Committee approved work with MERS-CoV strains under Biosafety Level 3 conditions.

\section{Viral Stock Propagation}

We provide strain-specific details for the viruses used in this study (Table). Viruses were isolated by others and provided for this study. SARS-CoV-2/Washington was isolated by the Centers for Disease Control and Prevention (Atlanta, GA, USA).

We obtained MERS-CoV strains from the following sources: EMC12 from Erasmus Medical Center (Rotterdam, the Netherlands); U/14, KSA/15, and KSA/18 from the Centers for Disease Control and Prevention; SK/15 from Chungbuk National University (Cheongju, South Korea); and C/KSA/13, $\mathrm{C} / \mathrm{E} / 13$, and $\mathrm{C} / \mathrm{BF} / 15$ from Hong Kong University (Hong Kong, China). We passaged MERS-CoV and SARS-CoV-2 strains once in Vero E6 cells in Dulbecco's modified Eagle medium (DMEM; Sigma Aldrich, https:/ / www.sigmaaldrich.com) supplemented with $2 \%$ fetal bovine serum (Thermo Fisher Scientific, https://www.thermofisher.com), $50 \mathrm{U} / \mathrm{mL}$ of penicillin (Thermo Fisher), and $50 \mu \mathrm{g} / \mathrm{m}$ of streptomycin (Thermo Fisher).

We maintained Vero E6 cells in DMEM supplemented with $10 \%$ fetal bovine serum, $1 \mathrm{mmol} / \mathrm{L}$ of L-glutamine, $50 \mathrm{U} / \mathrm{mL}$ of penicillin, and $50 \mu \mathrm{g} /$ $\mathrm{mL}$ of streptomycin. We clarified virus stocks by

\begin{tabular}{|c|c|c|c|c|c|c|}
\hline Name & Host & Year & Location & Full name & $\begin{array}{c}\text { GenBank } \\
\text { accession no. }\end{array}$ & SNPs $>50 \%$ \\
\hline $\mathrm{EMC} / 12$ & Human & 2012 & Saudi Arabia & HCoV-EMC/2012 & JX869059 & G27162A (ORF5, W108†) \\
\hline $\mathrm{U} / 14$ & Human & 2014 & United States & Hu/Florida/USA-2/Saudi Arabia/2014 & KP223131 & None \\
\hline KSA/15 & Human & 2015 & Saudi Arabia & Hu/Hofuf/KSA-11002/2015 & KY688120 & None \\
\hline SK/15 & Human & 2015 & South Korea & Hu/Korea/Seoul/177-3/2015 & KX034100 & $\begin{array}{l}\text { C2149A (NSP2, S431Y); } \\
\text { A6884G (synonymous); } \\
\text { T9566C (synonymous); } \\
\text { G10155T (NSP5, A46S); } \\
\text { A11376T (NSP6, S147C); } \\
\text { C14162T (synonymous); } \\
\text { C26189T (ORF4b R33C) }\end{array}$ \\
\hline $\mathrm{KSA} / 18$ & Human & 2018 & Saudi Arabia & Hu/Saudi Arabia/3015600912/2018 & MN723544 & $\begin{array}{l}\text { C21149A (NSP16, L183I); } \\
\text { G22366A† (S, R304Q); } \\
\text { C25009T (S, S1185L) }\end{array}$ \\
\hline $\mathrm{C} / \mathrm{KSA} / 13$ & Camel & 2013 & Saudi Arabia & Camel/Saudi Arabia/KFU-HKU1/2013 & KJ650297 & $\begin{array}{l}\text { C25207T (S, S1251F); } \\
\text { C27875T (M, T8I) }\end{array}$ \\
\hline $\mathrm{C} / \mathrm{E} / 13$ & Camel & 2013 & Egypt & Camel/Egypt/NRCE/HKU270/2013 & KJ477103 & $\begin{array}{c}\text { T16318C (synonymous); } \\
\text { C24112T (S, A886V); 26892T } \\
\text { (ORF5, P18L) }\end{array}$ \\
\hline C/BF/15 & Camel & 2015 & Burkina Faso & $\begin{array}{c}\text { Camel/Burkina Faso/CIRAD- } \\
\text { HKU785/2015 }\end{array}$ & MG923471 & None \\
\hline
\end{tabular}

${ }^{*}$ NSP, nonstructural protein; ORF, open reading frame; SNP, single-nucleotide polymorphism. †Present in other sequences. 
centrifugation and froze them at $-80^{\circ} \mathrm{C}$. We performed virus titrations by using endpoint titration in Vero E6 cells inoculated with 10-fold serial dilutions of virus. We scored cytopathic effect at day 5 (for MERS-CoV) or day 6 (for SARS-CoV-2) and calculated median tissue culture infectious dose $\left(\mathrm{TCID}_{50}\right)$ from 4 replicates by using the SpearmanKarber method (22).

\section{Sequencing Stocks}

We treated MERS-CoV samples with RiboZero H/M/R rRNA Depletion Mix (Illumina, https:// www.illumina.com) according to the manufacturer's instructions. After purification with Ampure RNACleanXP (Beckman Coulter, ttps://www.beckmancoulter.com), we eluted enriched RNA and assessed it on a BioAnalyzer RNA Pico Chip (Agilent Technologies, https://www.agilent.com). We prepared second-strand cDNA according to the Truseq Stranded mRNA Library Preparation Guide (Illumina). We treated samples with RiboShredder RNase Blend (https://www.cambio.co.uk).

We visualized final libraries on a BioAnalyzer DNA1000 Chip (Agilent Technologies), and quantified them by using a KAPA Library Quant Kit (Illumina) and a universal qPCR Mix (Kapa Biosystems, https://www.roche.com) on a CFX96 Real-Time System (Bio-Rad Laboratories, https://www.biorad.com). We pooled libraries together in equimolar concentrations and sequenced them using MiSeq (Illumina) with on-board cluster generation and $2 \times 250$ paired-end sequencing. The cluster density was at $454 \mathrm{k} / \mathrm{mm}^{2} /$ lane, resulting in 8.7 million reads passing filter/run and an average $85 \%$ greater than the Q30 score.

\section{Phylogenetics}

We downloaded all available MERS-CoV genome sequences from GenBank and curated them to remove sequences that were not independently sampled. We aligned sequences with the consensus sequences for MERS-CoV isolates used in this study by using MAFFT version 7.388 plugin (23) in Geneious Prime (https://www.geneious.com). We inferred a phylogenetic tree by using the maximum-likelihood method under the general time reversible plus gamma model of nucleotide substitution with 1,000 bootstrap replicates implemented with PhyML version 3.3.20190321 (https:/ / www.atgc-montpellier.fr).

\section{Stability of MERS-CoV on Surfaces and in Aerosols}

We sterilized 15-mm polypropylene discs (ePlastics, https:/ / www.eplastics), AISI 304 alloy stainless steel discs (Metal Remnants, https:/ / metalremnants.com), copper discs (99.9\%; Metal Remnants), and silver discs (99.9\%) (Sigma-Aldrich, https:/ / www.sigmaaldrich.com), placed them in 24-well plates, and added $50 \mu \mathrm{L}$ of MERS-CoV $\left(10^{5} \mathrm{TCID}_{50} / \mathrm{mL}\right)$. For timepoints taken at $0,1,24,48$, and $72 \mathrm{~h}$, we added $1 \mathrm{~mL}$ of DMEM to wells, aliquoted, and stored at $-80^{\circ} \mathrm{C}$. We titrated samples on Vero E6 cells and maintained the temperature $\left(21^{\circ} \mathrm{C}-22^{\circ} \mathrm{C}\right)$ and humidity $(45 \%-55 \%)$.

We determined virus stability in aerosols as described (24). In brief, we loaded a collison nebulizer with $10^{6.5} \mathrm{TCID}_{50} / \mathrm{mL}$ of MERS-CoV in DMEM containing $2 \%$ fetal bovine serum. Aerosols were maintained in a Goldberg drum and samples collected at $0,30,60,120$, and $180 \mathrm{~min}$ after aerosolization by passing air at a volume of $6 \mathrm{~L} / \mathrm{min}$ for $30 \mathrm{~s}$ from the drum through a 47-mm gelatin filter (Sartorius, https://www.sartorius.com). Filters were dissolved in $10 \mathrm{~mL}$ of DMEM containing $10 \%$ fetal bovine serum and stored at $-80^{\circ} \mathrm{C}$. All samples were titrated on Vero E6 cells.

\section{Replication of MERS-CoV Strains In Vitro}

We inoculated Vero E6 cells with virus (multiplicity of infection $=0.01$ ) and collected supernatants at 8 , 24, 48 and 72 hours postinfection (hpi). Human airway epithelium (HAE) inserts (Epithelix, https:// www.epithelix.com) were maintained as specified by the manufacturer. We washed HAEs with $200 \mu \mathrm{L}$ of phosphate-buffered saline for $30 \mathrm{~min}$, followed by inoculation with MERS-CoV at a multiplicity of infection of 0.1 . We obtained samples at $8,24,48,72$, and 96 hpi.

\section{Animal Experiments}

We inoculated intranasally transgenic BALB/c mice expressing human DPP4 with $10^{3} \mathrm{TCID}_{50}$ MERS$\mathrm{CoV}$. Mice were weighed and swabbed daily. At day 3 , we euthanized 4 mice and harvested lung tissue. We monitored the remaining 6 mice for survival. We euthanized mice if there were signs of severe disease signs based on quantitative assessment (e.g., hunched posture, lack of movement) or $>20 \%$ weight loss.

\section{RNA Extraction and Quantitative Reverse Transcription PCR}

We homogenized lung tissues and extracted RNA by using the RNeasy method (QIAGEN, https://www. qiagen.com) according to the manufacturer's instructions. We added swab specimens to $1 \mathrm{~mL}$ of DMEM, vortexed them, and used $140 \mu \mathrm{L}$ for RNA extraction by using the QiaAmp Viral RNA Kit and a QIAxtractor (QIAGEN). 
We detected MERS-CoV viral RNA by using the UpE MERS-CoV assay (25) and the RotorGeneTM Probe Kit (QIAGEN). Primers in this assay target a highly conserved region upstream of MERS-CoV envelope gene. Sequences of MERS$\mathrm{CoV}$ strains used in this study are identical in this region. MERS-CoV dilutions with known genome copies were run in parallel to enable calculation of genome copies in samples.

\section{Histologic and Immunohistochemical Analysis}

We fixed harvested tissues for $\geq 7$ days in $10 \%$ neutral-buffered formalin, processed them by using a VIP-6 Tissue Tek Tissue Processor (Sakura Finetek, https://www.sakuraus.com), and embedded them in Ultraffin Paraffin Polymer (Cancer Diagnostics, https://www.cancerdiagnostics.com). We stained $5-\mu \mathrm{m}$ sections with hematoxylin and eosin and detected coronavirus immunoreactivity by using MERS-CoV nucleocapsid protein rabbit antibody (diluted 1:4,000; Sino Biological Inc, https://www. sinobiological.com).

We processed tissues for immunohistochemical analysis by using the Discovery ULTRA Automated IHC/ISH Staining Instrument (and a Discovery ChromoMap DAB Kit (both from Ventana Medical Systems, https://diagnostics.roche.com). For morphometric analysis, we scanned slides by using the Aperio ScanScope AT2 (Aperio Technologies, Inc., https://www.aperio.com) and analyzed the entire section by using ImageScope Positive Pixel Count Algorithm version 9.1 (Aperio Technologies, Inc.). All tissue slides were evaluated by a board-certified veterinary anatomic pathologist.

\section{Statistical Analyses}

We performed analyses by using GraphPad Prism version 7.05 for Windows (https:/ / www.graphpad. com). All strains were compared with EMC/12. For aerosol stability data analysis, we determined linear regression for the mean value of 3 runs/virus. We determined statistical significance in deviation from MERS-CoV/EMC12 results by using 1-way analysis of variance, followed by the Bonferroni multiple comparisons test or a 2-way unpaired Student's ttest. We used simple linear regression to evaluate slopes of decay. Survival of mice compared with mice inoculated with EMC/12 was performed by using the log-rank (Mantel-Cox) test. To calculate the amount of virus shedding per mouse in in vivo comparisons, we calculated the area under the curve for a plot of the viral load measured in oropharyngeal swab specimens.

\section{Results}

\section{Stability of MERS-CoV Strains in Aerosols or as Fomi- tes Compared with SARS-CoV-2}

We selected 8 MERS-CoV strains and 1 SARS-CoV-2 strain (SARS-CoV-2/WA1-2020) to be used in this study (Table; Figure 1). Five MERS-CoV strains were isolated from human cases and 3 strains were isolated from dromedary camels. Strains were isolated during 2012-2018 and originated from the Middle East (5), Africa (2) or South Korea (1) (Table). All originally obtained viruses were passaged once in Vero E6 cells, and virus stocks were deep sequenced (Table). We used MERS-CoV sequences to construct a phylogenetic maximum-likelihood tree, which showed a wide distribution of MERS-CoV strains selected. Thus, our panel represents a broad sample of known genetic variation within currently circulating MERS$\mathrm{CoV}$ strains.

We first investigated the stability of MERS-CoV as fomites on polypropylene, stainless-steel, copper, and silver surfaces, which we selected because they represent commonly encountered surfaces in hospital environments or have virocidal properties (23). For comparison with a pandemic human coronavirus, we also included SARS-CoV-2. Back-titrations of all virus strains showed comparable starting virus titers. Stability of MERS-CoV on polypropylene and stainless-steel surfaces, maintained at $21^{\circ} \mathrm{C}-22^{\circ} \mathrm{C}$ and a relative humidity of $45 \%-55 \%$ under standard laboratory light conditions, was similar to that reported for MERS-CoV and SARS-CoV-2 stability on surfaces $(21,26)$. We found major differences in decay rates when comparing EMC/12 to SK/15, KSA/18, C/ $\mathrm{KSA} / 13$, and $\mathrm{C} / \mathrm{BF} / 15$ on polypropylene. These differences were not found for the other surfaces (Figure 2; Appendix Figure, https://wwwnc.cdc.gov/EID/ article/27/12/21-0344-App1.pdf). Infectious virus titers were low for all strains on copper and silver surfaces at 24 hours. We analyzed data by using linear regression for the first 24 hours for each surface and each virus. Decay, averaged between all virus strains, was higher for copper $\left(-0.11576 \log _{10} \mathrm{TCID}_{50} / \mathrm{h}\right)$ and silver $\left(-0.08744 \log _{10} \mathrm{TCID}_{50} / \mathrm{h}\right)$ surfaces than for polypropylene $\left(-0.0529 \log _{10} \mathrm{TCID}_{50} / \mathrm{h}\right)$ and stainlesssteel $\left(-0.0469 \log _{10} \mathrm{TCID}_{50} / \mathrm{h}\right)$ surfaces.

We aerosolized all MERS-CoV strains in a Goldberg drum at $21^{\circ} \mathrm{C}$ and a relative humidity of $60 \%-70 \%$ in the dark. We then tested samples at $0,30,60,120$ and $180 \mathrm{~min}$ after aerosolization, titrated them, and compared results with those for SARS-CoV-2. We detected no major differences in linear regression of loss of infectious virus in aerosols between strains. For all 


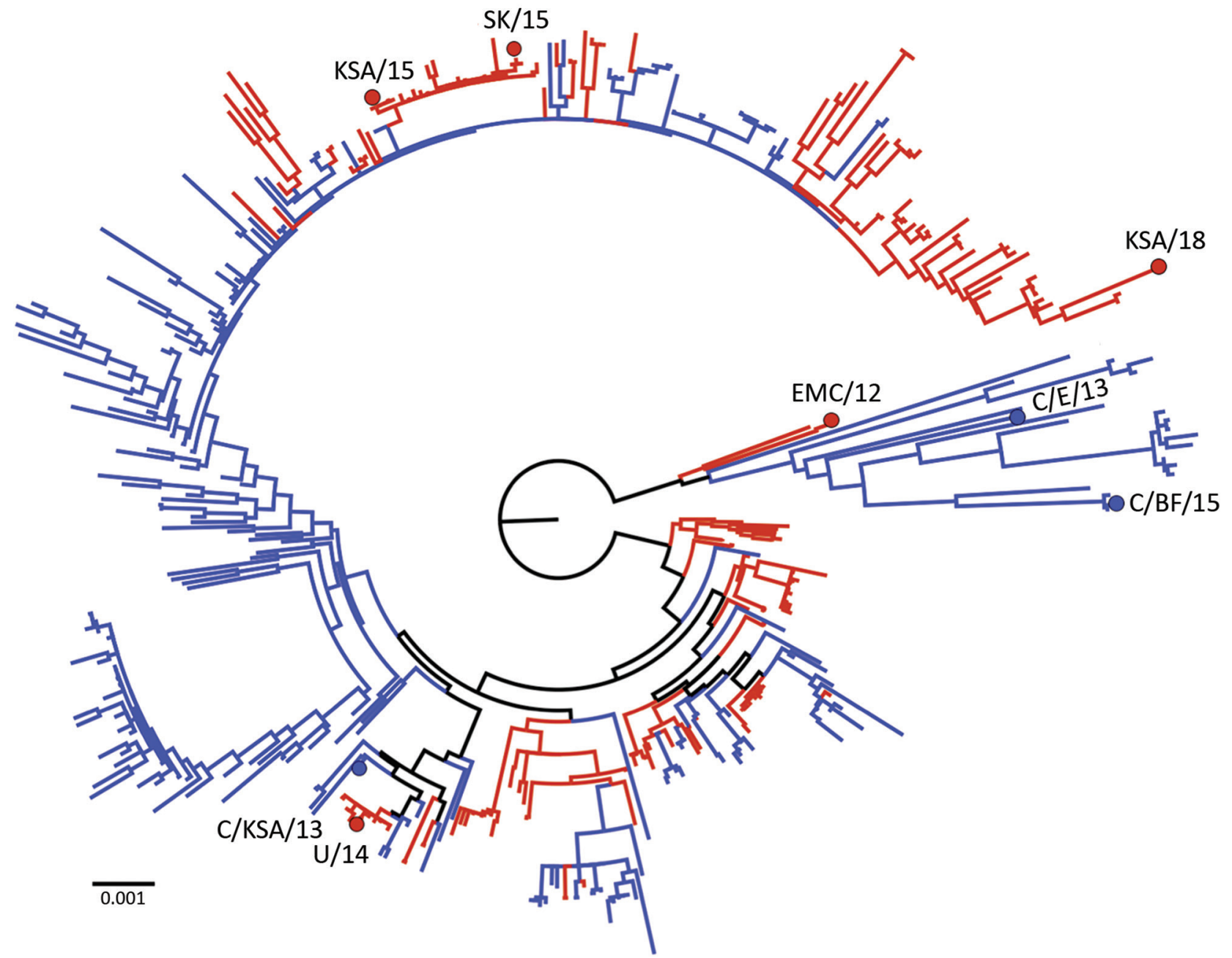

Figure 1. Phylogenetic tree of 446 full Middle East respiratory syndrome coronavirus (MERS-CoV) genomes showing distribution of human-derived (red) and camel-derived (blue) isolates. The tree was constructed with PhyML (https://www.atgc-montpellier.fr) and rooted at the midpoint. Strain EMC/12 was obtained from Erasmus Medical Center (Rotterdam, the Netherlands); U/14, KSA/15, and KSA/18 from the Centers for Disease Control and Prevention (Atlanta, GA, USA); SK/15 from Chungbuk National University (Cheongju, South Korea); and C/KSA/13, C/E/13, and C/BF/15 from Hong Kong University (Hong Kong, China). Scale bar indicates nucleotide substitutions per site. KSA, Kingdom of Saudi Arabia.

MERS-CoV strains, infectious virus could still be detected at $180 \mathrm{~min}$ after aerosolization (Figure 2, panel B).

\section{In Vitro Replication of MERS-CoV Strains}

To investigate any in vitro growth differences, we grew strains in 2 cell systems, Vero E6 cells and HAE cultures, in comparison to the reference strain EMC/12. At 48 hpi, C/KSA/13 and KSA/15 showed higher titers than EMC/12 in Vero E6 cells. At 72 hpi, $\mathrm{C} / \mathrm{KSA} / 13$ and $\mathrm{C} / \mathrm{BF} / 15$ showed lower titers than EMC/12 in HAE cultures. We observed no other major differences in either culture type. Although differences were not always statistically significant, all camel-derived viruses had reduced replication kinetics compared with those for EMC/12 in HAE cells at 24-72 hpi (Figure 3).

\section{Disease Progression for MERS-CoV Strains in hDPP4 Transgenic Mice}

MERS-CoV enters cells expressing the receptor human dipeptidyl peptidase IV (hDPP4). Our laboratory developed hDPP4 transgenic mice to test MERS$\mathrm{CoV}$ vaccine efficacy (20). We intranasally inoculated 10 mice/group with $10^{3} \mathrm{TCID}_{50}$ MERS-CoV/mouse. Mice started to lose weight on days 2-5 postchallenge; weight continued to decrease for all groups, except for mice inoculated with $\mathrm{C} / \mathrm{BF} / 15$, in which only 1 mouse continued to lose weight (Figure 4, 
panel A). For all groups, including C/BF/15, weight loss was also associated with other signs: ruffled coat, increased breathing rate, reluctance to move, and hunched posture. Only animals in the groups inoculated with SK/15 (1/6) and the group inoculated with $\mathrm{C} / \mathrm{BF} / 15(5 / 6)$ survived. Average time to
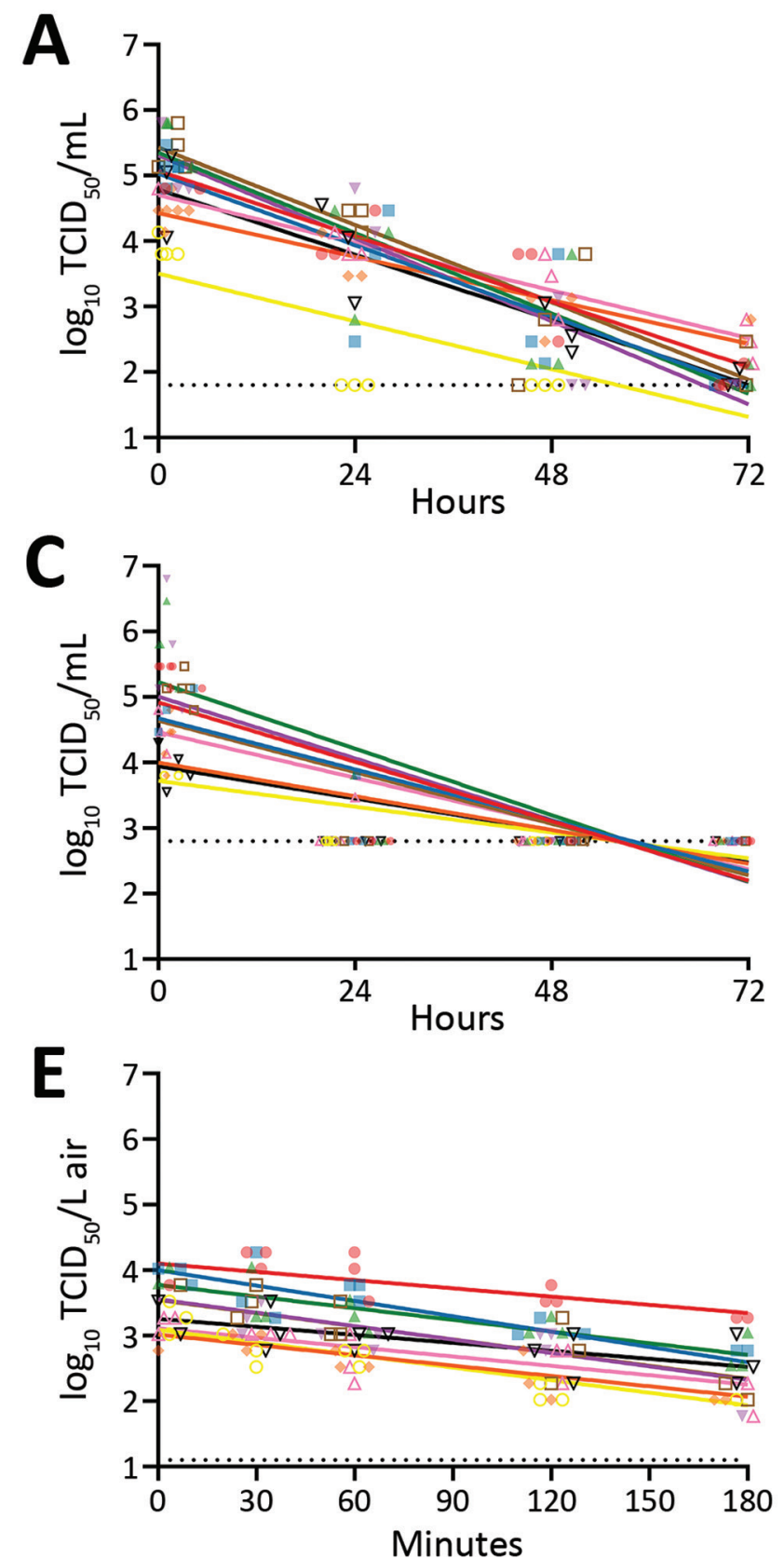

death was similar for all groups, excluding $\mathrm{C} / \mathrm{BF} / 15$ : $\mathrm{EMC} / 12,7.33$ days; $\mathrm{U} / 14,6.5$ days; KSA/15. 7 days; SK/15. 7.6 days; KSA/18. 7.67 days; C/KSA/13, 7.5 days; and $\mathrm{C} / \mathrm{E} / 13,8$ days (Figure 4, panel B).

We measured viral RNA in oral swab specimens obtained during days 1-7 postchallenge and found no
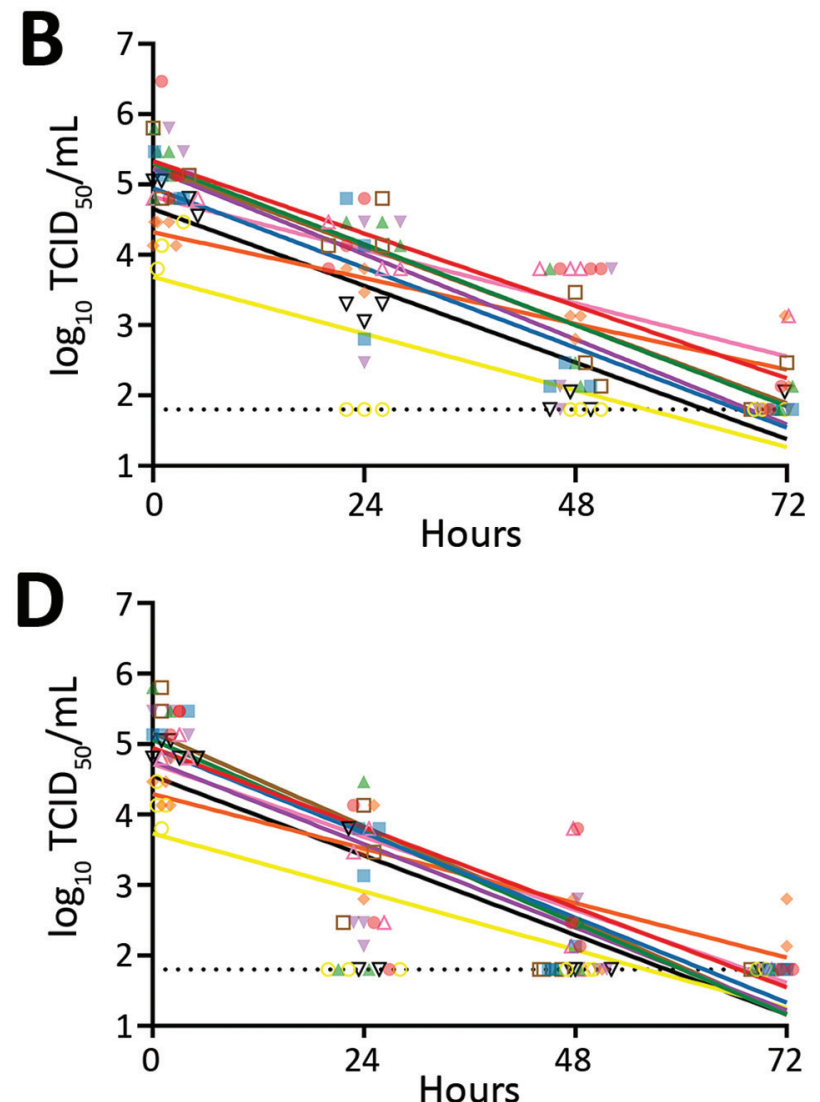

- EMC/12

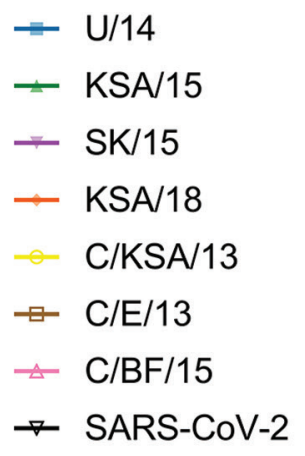

Figure 2. Stability of MERS-CoV strains on surfaces and in aerosols compared with those for SARS-CoV-2. Simple linear regression of virus was used for different surfaces and in aerosols. For surface stability, $50 \mu \mathrm{L}$ of MERS-CoV or SARS-CoV-2 was spread on a surface, either polypropylene, stainless steel, copper, or silver; $1 \mathrm{~mL}$ of Dulbecco's modified Eagle medium was added at times $0,1,24,48$, or 72 hours, and samples were titrated. For aerosol stability, MERS-CoV-or SARS-CoV-2-containing aerosols were sprayed into a Goldberg drum; samples were taken at times $0,30,60,120$, and 180 min and then titrated. Linear regression was calculated per virus and indicated as lines. Dotted lines indicate limits of detection. Strain sources are listed in the legend for Figure 1. MERS-CoV, Middle East respiratory syndrome coronavirus; SARS-CoV-2, severe acute respiratory syndrome coronavirus 2; $\mathrm{TCID}_{50}$, median tissue culture infectious dose. 

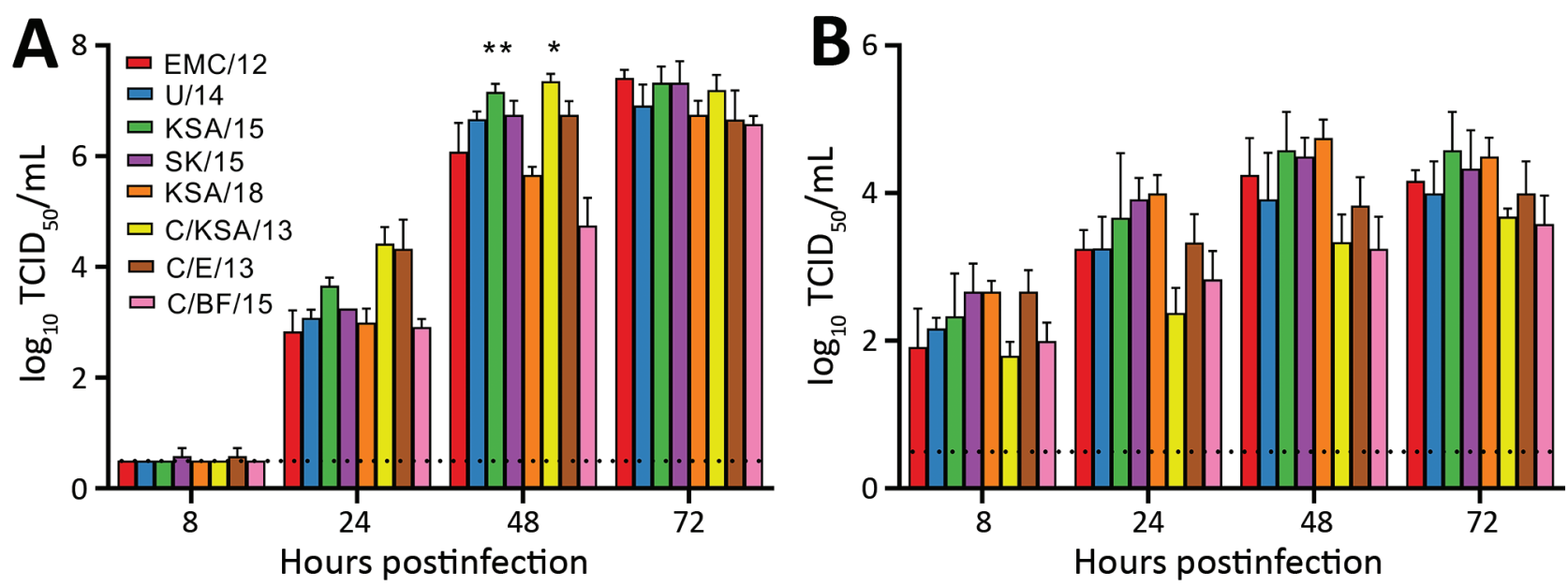

Figure 3. Middle East respiratory syndrome coronavirus replication in Vero E6 cells (A) and human airway epithelium (B). Replication is shown as geometric means; error bars indicate SDs. Vero E6 cells were infected with a multiplicity of infection of 0.01 , and human airway epithelium were infected with a multiplicity of infection of 0.1 . Samples of supernatants were obtained at $8,24,48$ and 72 hours postinoculation and titrated. Statistically significant differences compared with those for the prototypical strain, EMC/12, were calculated by using ordinary 1-way analysis of variance, followed by a Bonferroni multiple comparisons test. Dotted lines indicate limits of detection. Strain sources are listed in the legend for Figure 1. $\mathrm{TCID}_{50}$, median tissue culture infectious dose. ${ }^{*} p<0.05 ;{ }^{* *} p<0.01$.

major differences in the amount of shedding between different groups (Figure 4, panels C, D). Viral genome RNA was lower in lung tissue collected on day 3 from mice inoculated with SK/15, C/E/15, and C/BF/15. Subgenomic RNA was lower to a major degree only in lung tissue of mice inoculated with C/BF/15 (Figure 4, panels E, F).

We observed no differences in pathology between different groups. Animals rarely showed pulmonary pathology at day 3. However, animals that had lesions showed only a minimal and random lymphocytic infiltrate. Immunohistochemical analysis showed that MERS-CoV antigen was expressed rarely or randomly in type I and II pneumocytes and not located in areas of inflammation. Morphometric analysis of pulmonary tissue that had immunoreactivity showed no major differences between groups (Figure 4, panel G).

\section{Discussion}

The ongoing MERS-CoV endemic in the Middle East and subsequent discovery of the virus in camel herds across Africa has resulted in a wealth of publicly available genetic data for various viral strains and isolates. In this study, we assessed several of these isolates for viral phenotypes related to public health in an attempt to better inform public health policy making with regards to MERS-CoV and other human coronaviruses that cause respiratory diseases, such as SARS-CoV-2.

Because nosocomial spread is at the center of MERS-CoV outbreaks, we assessed the stability of the virus on various surface material types commonly found in hospitals (polypropylene plastic and stainless steel), as well as materials that had potential antiviral and known antimicrobial properties (silver and copper) $(27,28)$. Our experiments were performed at environmental conditions similar to those in hospitals, in which there is high risk for human-to-human, nosocomial transmission. Regardless of the surface material tested, strain C/KSA/13 was the least stable over time and was below detectable levels by 24 hours (Figures 2,4). This strain had the lowest starting titer in these experiments, which might explain this difference in stability. In addition, our C/KSA/13 stock contains 2 nonsynonymous mutations in the viral structural proteins, spike and matrix, not found in our other strains, which might also play a role in this difference, either directly or indirectly (Table). These findings warrant further studies on how specific MERS-CoV polymorphisms in structural proteins affect viral growth.

As shown by Doremalen et al. (21), all virus strains tested had notably reduced stability on copper and silver surfaces (Figure 2, panel A). Copper has been shown to also have antiviral properties against influenza $\mathrm{A}(\mathrm{H} 1 \mathrm{~N} 1)$ virus and SARS-CoV-2 (29-31). The exact antiviral mechanism for copper is still unclear, but might be related to formation of hydroxyl radicals by copper ions when in aqueous solution (31). Silverbased nanoparticles have been shown to be antiviral for HIV-1 (32), herpes simplex virus 2 (33), hepatitis B virus (34), respiratory syncytial virus (35), and 
monkeypox virus (36). Taking advantage of the antiviral properties of copper and silver might help decrease nosocomial transmission. Both silver and copper can be used for coating medical tools (37) and commonly touched items, such as bed rails, door handles, and intravenous poles (38). These findings appear to be more broadly applicable for other coronaviruses because we observed similar results for SARS-CoV-2 (Figure 2) (21). Further research should be invested in determining coronavirus susceptibility to metal ion inactivation.

MERS-CoV transmission might occur through aerosols and fomites (39), although the role of each route is not known. Transmission often occurs in hospitals; thus, aerosol-generating medical procedures might play a major role (40). MERS-CoV transmission has occurred over distances of $>6$ feet (41), and evidence of MERS-CoV on surfaces and in air in hospitals has been found (39). Studies have suggested that a hospital air-handling system might have contributed to nosocomial spread during the 2015 MERS-CoV outbreak in South Korea $(14,39)$, and our group has shown that the virus can remain viable suspended in air for $\leq 10 \mathrm{~min}(26)$. We tested aerosol stability of viral isolates and observed that all viruses remained viable for a minimum of $180 \mathrm{~min}$ with an $\approx 10$-fold
A

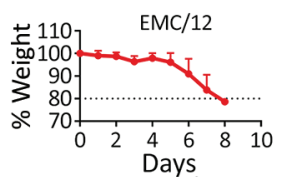
postinoculation

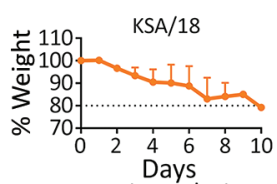

postinoculation

B

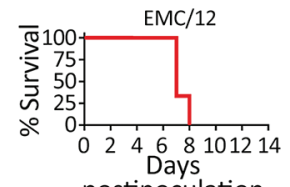

postinoculation

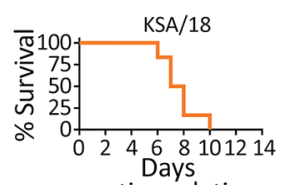

postinoculation

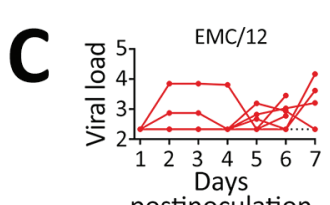

postinoculation

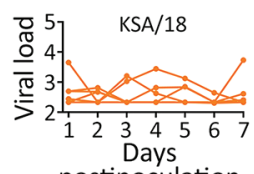

postinoculation

D

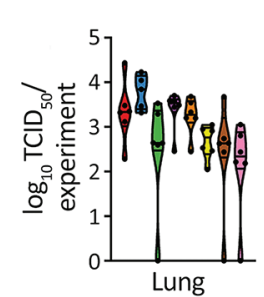

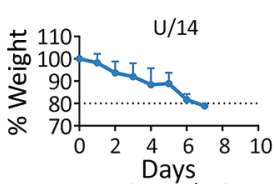

postinoculation
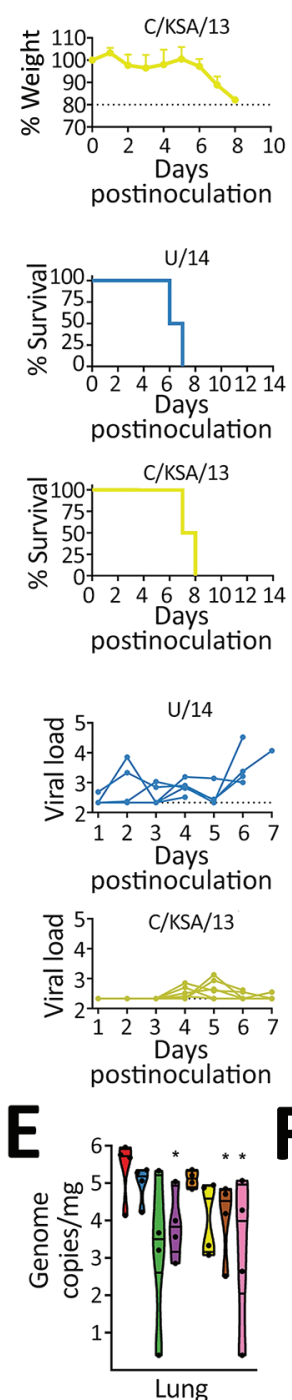
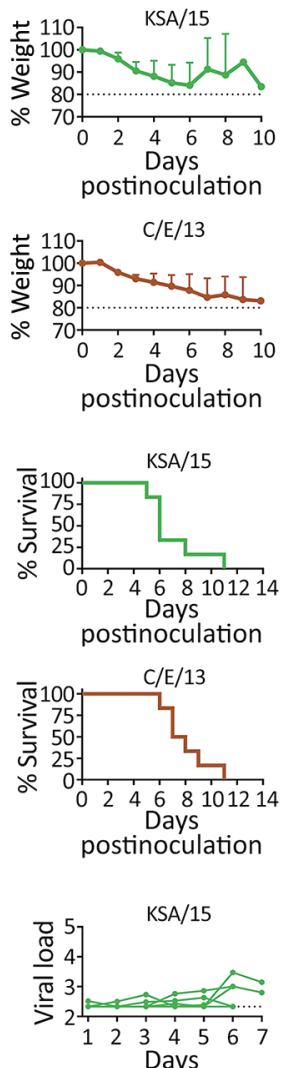

postinoculation

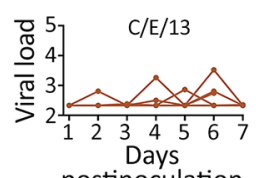

postinoculation

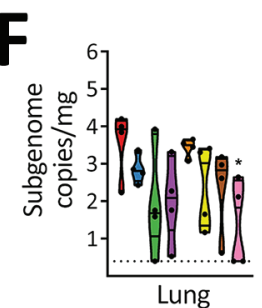

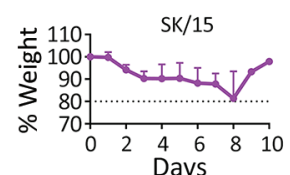
postinoculation
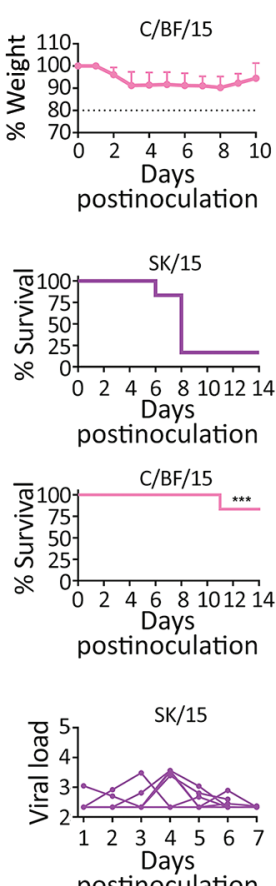

postinoculation

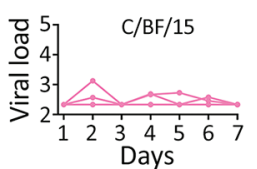

postinoculation

G

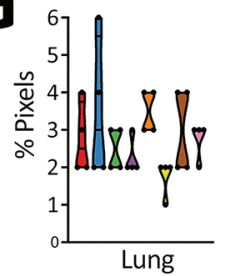

Figure 4. In vivo replication of different Middle East respiratory syndrome coronavirus (MERSCoV) strains. hDPP4 mice were inoculated intranasally with $10^{3}$ TCID $_{50}$ of MERS-CoV. Four mice were euthanized on day 3 , and the remaining 6 mice were monitored for survival. A) Relative weight loss of hDPP4 mice. B) Survival of hDPP4 mice. C) Oropharyngeal shedding of MERS-CoV as measured by using an UpE quantitative reverse transcription PCR. D) Amount of shedding per experiment per mouse calculated by using area under the curve (AUC) analysis of viral load in oropharyngeal swab specimens. Results are displayed per mouse per virus strain. E) Viral load in lung tissue obtained from mice euthanized at day 3 .

F) Viral mRNA load in lung tissue obtained from mice euthanized at day 3. G) Percentage of positive pixels quantified from lung tissues stained for MERS-CoV antigen. Colors in panels D-F match those for strains in panels A--C; strain sources are listed in the legend for Figure 1. Statistical significance was compared by using 1-way analysis of variance, followed by a Bonferroni multiple comparisons test. Dotted lines indicate limits of detection. $\mathrm{TCID}_{50}$, median tissue culture infectious dose. ${ }^{*} p<0.05$. 
reduction in viral titer observed on average within the collected aerosols (Figure 2, panel B).

Although we did not observe major differences in this study, strain stability is an useful phenotype to continue monitoring because mutations in viral capsid proteins have been shown to enhance environmental stability of bacteriophages, dengue virus, and transmissible gastroenteritis virus (42-44). Because MERS-CoV isolates contain polymorphisms throughout the entire viral genome, including the structural proteins that form virions, mutations might arise that influence overall virus particle stability. C/KSA/13, which showed reduced stability on surfaces in our experiments, contains polymorphisms in open reading frame $1 b$, the spike glycoprotein, and the virion matrix protein in comparison to the other strains tested. Recent studies have further demonstrated the influence of various external factors on environmental stability for SARS-CoV-2, including experimental ambient conditions and matrix in which the virus is suspended $(45,46)$. Our experiments were performed in standard, indoor laboratory settings and with virus suspended in culture media, which enabled us to observe intrinsic differences determined solely at the viral level. Tracking and assessing the stability of coronavirus strains will improve our understanding of coronavirus variant spread.

We tested viral replication kinetics in Vero E6 cells and primary HAE cells (Figure 3 ). All viruses replicated to similar titers on Vero E6 cells by 72 hours. However, KSA/15 and C/KSA/13 had higher titers than $\mathrm{EMC} / 12$ by 48 hpi. Albeit the difference is not significant, C/BF/15 has a lower viral titer than EMC/12 at 48 hpi and $72 \mathrm{hpi}$. These results are consistent with those of a previous study, which showed that $\mathrm{C} / \mathrm{BF} / 15$ has impaired replication (18). In primary HAE cultures, all camel-derived viral isolates had reduced replication kinetics compared with that for EMC/12 (Figure 3, panel B). More studies are needed with these camelderived isolates to determine whether their differences in replication kinetics results from a comparison with EMC12, which has well-described tissue culture adaptations, or to see if MERS-CoV might adapt in humans after transmission from camels. Sequence analysis of the viral variants did not identify any obvious mutation patterns in any single viral protein that would explain the differences in replication kinetics. Thus, we speculate that these differences are the result of cumulative effects across $\geq 1$ types of genetic variation.

We have shown that MERS-CoV replicates in type I and II pneumocytes in the lower respiratory tract of an animal model (20). Although disease progression after infection with this virus does not involve the central nervous system in humans, this small animal model is suitable for vaccine candidate testing, using animal survival or viral-induced death as a binary readout for vaccine efficacy. MERS-CoV C/BF/15 contains a deletion in open reading frame $4 \mathrm{~b}$, which has been shown in a similar mouse model to result in impaired suppression of the host interferon response and increased type I and type III interferon signaling (18). Taken together, these results pave the way for testing MERS-CoV vaccine candidates for broadly neutralizing potential in this animal model $(20,47)$.

Our results with MERS-CoV C/KSA/13 suggest there might be a potential tradeoff between environmental surface stability and replication kinetics. This tradeoff was observed for a camel-derived isolate, and we did not observe similar phenotypic relationships for the other strains tested (Figures 2, 3). Future research efforts with camel-derived viruses and more closely related human-derived viruses could show whether adaptations are likely to occur after zoonosis. Our previous viral stability results with SARS-CoV-2 and the findings of this study with MERS-CoV suggest copper should be incorporated more in hospital settings, particularly in materials in areas of high contact between hospital workers and MERS patients, such as door handles, bed rails, and medical tools (21). Overall, we observed a range of stability, replication, and pathogenesis phenotypes between different MERS-CoV isolates, underscoring the need for continued surveillance of this virus and other coronaviruses, including SARS-CoV-2.

\section{Acknowledgments}

We thank the animal caretakers for providing assistance during the animal studies.

This study was supported by the Intramural Research Program of the National Institute of Allergy and Infectious Diseases, National Institutes of Health (grant 1ZIAAI001179-01).

\section{About the Authors}

Dr. van Doremalen is an associate scientist in the Virus Ecology Section, National Institutes of Health Rocky Mountain Laboratories, Hamilton, MT. Her primary research interests are development of coronavirus animal models and next-generation vaccines for emerging infectious diseases, including the Oxford/Astrazeneca COVID-19 vaccine.

Dr. Letko is an assistant professor at the Paul G. Allen School of Global Health, Washington State University, Pullman, WA. His primary research interests are virushost molecular interactions and zoonotic transmission of novel, animal-derived viruses. 


\section{References}

1. Zaki AM, van Boheemen S, Bestebroer TM, Osterhaus $\mathrm{AD}$, Fouchier RA. Isolation of a novel coronavirus from a man with pneumonia in Saudi Arabia. N Engl J Med. 2012;367:1814-20. https://doi.org/10.1056/NEJMoa1211721

2. World Health Organization. MERS situation update, October 2019 [cited 2021 Aug 26]. http:/ / www.emro.who.int/ pandemic-epidemic-diseases/mers-cov/mers-situationupdate-october-2019.html

3 Zhang W, Zheng XS, Agwanda B, Ommeh S, Zhao K, Lichoti J, et al. Serological evidence of MERS-CoV and HKU8-related CoV co-infection in Kenyan camels. Emerg Microbes Infect. 2019;8:1528-34. https:/ / doi.org/10.1080/ 22221751.2019.1679610

4. van Doremalen N, Hijazeen ZS, Holloway P, Al Omari B, McDowell C, Adney D, et al. High prevalence of Middle East respiratory coronavirus in young dromedary camels in Jordan. Vector Borne Zoonotic Dis. 2017;17:155-9. https:/ / doi.org/10.1089/vbz.2016.2062

5. Shirato K, Melaku SK, Kawachi K, Nao N, Iwata-Yoshikawa N, Kawase M, et al. Middle East respiratory syndrome coronavirus in dromedaries in Ethiopia is antigenically different from the Middle East isolate EMC. Front Microbiol. 2019;10:1326. https://doi.org/10.3389/ fmicb.2019.01326

6. Kandeil A, Gomaa M, Nageh A, Shehata MM, Kayed AE, Sabir JSM, et al. Middle East respiratory syndrome coronavirus (MERS-CoV) in dromedary camels in Africa and Middle East. Viruses. 2019;11:11. https:/ / doi.org/10.3390/ v11080717

7. Farag E, Sikkema RS, Mohamedani AA, de Bruin E, Munnink BB, Chandler F, et al. MERS-CoV in camels but not camel handlers, Sudan, 2015 and 2017. Emerg Infect Dis. 2019;25:2333-5. https:// doi.org/10.3201/eid2512.190882

8. Chu DK, Poon LL, Gomaa MM, Shehata MM, Perera RA, Abu Zeid D, et al. MERS coronaviruses in dromedary camels, Egypt. Emerg Infect Dis. 2014;20:1049-53. https://doi.org/10.3201/eid2006.140299

9. Alagaili AN, Briese T, Mishra N, Kapoor V, Sameroff SC, Burbelo PD, et al. Middle East respiratory syndrome coronavirus infection in dromedary camels in Saudi Arabia. MBio. 2014;5:e00884-14. https://doi.org/10.1128/ mBio.01002-14

10. Miguel E, Chevalier V, Ayelet G, Ben Bencheikh MN, Boussini H, Chu DK, et al. Risk factors for MERS coronavirus infection in dromedary camels in Burkina Faso, Ethiopia, and Morocco, 2015. Euro Surveill. 2017;22:22. https:/ / doi.org/10.2807/1560-7917.ES.2017.22.13.30498

11. Chu DK, Oladipo JO, Perera RA, Kuranga SA, Chan SM, Poon LL, et al. Middle East respiratory syndrome coronavirus (MERS-CoV) in dromedary camels in Nigeria, 2015. Euro Surveill. 2015;20:20. https:// doi.org/10.2807/ 1560-7917.ES.2015.20.49.30086

12. Hui DS, Azhar EI, Kim YJ, Memish ZA, Oh MD, Zumla A. Middle East respiratory syndrome coronavirus: risk factors and determinants of primary, household, and nosocomial transmission. Lancet Infect Dis. 2018;18:e217-27. https:/ / doi.org/10.1016/S1473-3099(18)30127-0

13. Assiri A, McGeer A, Perl TM, Price CS, Al Rabeeah AA, Cummings DA, et al.; KSA MERS-CoV Investigation Team. Hospital outbreak of Middle East respiratory syndrome coronavirus. N Engl J Med. 2013;369:407-16. https://doi.org/10.1056/NEJMoa1306742

14. Cho SY, Kang JM, Ha YE, Park GE, Lee JY, Ko JH, et al. MERS-CoV outbreak following a single patient exposure in an emergency room in South Korea: an epidemiological outbreak study. Lancet. 2016;388:994-1001. https:/ / doi.org/10.1016/S0140-6736(16)30623-7

15. Chowell G, Abdirizak F, Lee S, Lee J, Jung E, Nishiura H, et al. Transmission characteristics of MERS and SARS in the healthcare setting: a comparative study. BMC Med. 2015;13:210. https:/ / doi.org/10.1186/s12916-015-0450-0

16. Hunter JC, Nguyen D, Aden B, Al Bandar Z, Al Dhaheri W, Abu Elkheir K, et al. Transmission of Middle East respiratory syndrome coronavirus infections in healthcare settings, Abu Dhabi. Emerg Infect Dis. 2016;22:647-56. https:// doi.org/10.3201/eid2204.151615

17. Kim KH, Tandi TE, Choi JW, Moon JM, Kim MS. Middle East respiratory syndrome coronavirus (MERS-CoV) outbreak in South Korea, 2015: epidemiology, characteristics and public health implications. J Hosp Infect. 2017;95:207-13. https:/ / doi.org/10.1016/j.jhin.2016.10.008

18. Chu DK, Hui KPY, Perera RA, Miguel E, Niemeyer D, Zhao J, et al. MERS coronaviruses from camels in Africa exhibit region-dependent genetic diversity. Proc Natl Acad Sci U S A. 2018;115:3144-9. https://doi.org/10.1073/ pnas. 1718769115

19. Letko M, Miazgowicz K, McMinn R, Seifert SN, Sola I, Enjuanes L, et al. Adaptive evolution of MERS-CoV to species variation in DPP4. Cell Rep. 2018;24:1730-7. https://doi.org/10.1016/j.celrep.2018.07.045

20. Munster VJ, Wells D, Lambe T, Wright D, Fischer RJ, Bushmaker T, et al. Protective efficacy of a novel simian adenovirus vaccine against lethal MERS-CoV challenge in a transgenic human DPP4 mouse model. NPJ Vaccines. 2017;2:28. https://doi.org/10.1038/s41541-017-0029-1

21. van Doremalen N, Bushmaker T, Morris DH, Holbrook MG, Gamble A, Williamson BN, et al. Aerosol and surface stability of SARS-CoV-2 as compared with SARS-CoV-1. N Engl J Med. 2020;382:1564-7. https:// doi.org/10.1056/NEJMc2004973

22. Karber G. Article on the collective handling of pharmacological array effort. Naunyn Schmiedebergs Arch Exp Pathol Pharmakol. 1931;162:480-3.

23. Katoh K, Standley DM. MAFFT multiple sequence alignment software version 7: improvements in performance and usability. Mol Biol Evol. 2013;30:772-80. https://doi.org/10.1093/molbev/mst010

24. Fischer RJ, Bushmaker T, Judson S, Munster VJ. Comparison of the aerosol stability of 2 strains of Zaire ebolavirus from the 1976 and 2013 outbreaks. J Infect Dis. 2016;214(suppl 3):S290-3. https://doi.org/10.1093/infdis/jiw193

25. Corman VM, Eckerle I, Bleicker T, Zaki A, Landt O, Eschbach-Bludau M, et al. Detection of a novel human coronavirus by real-time reverse-transcription polymerase chain reaction. Euro Surveill. 2012;17:17. https:/ / doi.org/ 10.2807/ese.17.39.20285-en

26. van Doremalen N, Bushmaker T, Munster VJ. Stability of Middle East respiratory syndrome coronavirus (MERS-CoV) under different environmental conditions. Euro Surveill. 2013;18:18. https://doi.org/10.2807/15607917.ES2013.18.38.20590

27. Grass G, Rensing C, Solioz M. Metallic copper as an antimicrobial surface. Appl Environ Microbiol. 2011;77: 1541-7. https://doi.org/10.1128/AEM.02766-10

28. Galdiero S, Falanga A, Vitiello M, Cantisani M, Marra V, Galdiero M. Silver nanoparticles as potential antiviral agents. Molecules. 2011;16:8894-918. https:/ / doi.org/10.3390/ molecules16108894

29. Noyce JO, Michels H, Keevil CW. Inactivation of influenza A virus on copper versus stainless steel surfaces. Appl Environ Microbiol. 2007;73:2748-50. https:/ / doi.org/ 10.1128/ AEM.01139-06 
30. Minoshima M, Lu Y, Kimura T, Nakano R, Ishiguro $H$, Kubota Y, et al. Comparison of the antiviral effect of solid-state copper and silver compounds. J Hazard Mater. 2016;312:1-7. https:// doi.org/10.1016/j.jhazmat.2016.03.023

31. Fujimori $Y$, Sato T, Hayata T, Nagao T, Nakayama M, Nakayama T, et al. Novel antiviral characteristics of nanosized copper (I) iodide particles showing inactivation activity against 2009 pandemic H1N1 influenza virus. Appl Environ Microbiol. 2012;78:951-5. https:// doi.org/10.1128/ AEM.06284-11

32. Lara HH, Ayala-Nuñez NV, Ixtepan-Turrent L, Rodriguez-Padilla C. Mode of antiviral action of silver nanoparticles against HIV-1. J Nanobiotechnology. 2010;8:1. https://doi.org/10.1186/1477-3155-8-1

33. Hu RL, Li SR, Kong FJ, Hou RJ, Guan XL, Guo F. Inhibition effect of silver nanoparticles on herpes simplex virus 2 . Genet Mol Res. 2014;13:7022-8. https:// doi.org/10.4238/ 2014.March.19.2

34. Lu L, Sun RW, Chen R, Hui CK, Ho CM, Luk JM, et al. Silver nanoparticles inhibit hepatitis B virus replication. Antivir Ther. 2008;13:253-62.

35. Yang XX, Li CM, Huang CZ. Curcumin modified silver nanoparticles for highly efficient inhibition of respiratory syncytial virus infection. Nanoscale. 2016;8:3040-8. https://doi.org/10.1039/C5NR07918G

36. Rogers J, Parkinson C, Choi YW, Speshock JL, Hussain SM. A preliminary assessment of silver nanoparticle inhibition of monkeypox virus plaque formation. Nanoscale Res Lett. 2008;3:129-33. https://doi.org/10.1007/s11671-008-9128-2

37. Cyphert EL, von Recum HA. Emerging technologies for long-term antimicrobial device coatings: advantages and limitations. Exp Biol Med (Maywood). 2017;242:788-98. https:/ / doi.org/10.1177/1535370216688572

38. Salgado CD, Sepkowitz KA, John JF, Cantey JR, Attaway HH, Freeman KD, et al. Copper surfaces reduce the rate of healthcare-acquired infections in the intensive care unit. Infect Control Hosp Epidemiol. 2013;34:479-86. https://doi.org/10.1086/670207

39. Kim SH, Chang SY, Sung M, Park JH, Bin Kim H, Lee $\mathrm{H}$, et al. Extensive viable Middle East respiratory syndrome (MERS) coronavirus contamination in air and surrounding environment in MERS isolation wards. Clin Infect Dis. 2016;63:363-9. https:/ / doi.org/10.1093/cid/ ciw239
40. Judson SD, Munster VJ. Nosocomial transmission of emerging viruses via aerosol-generating medical procedures. Viruses. 2019;11:11. https://doi.org/10.3390/v11100940

41. Park YS, Lee C, Kim KM, Kim SW, Lee KJ, Ahn J, et al. The first case of the 2015 Korean Middle East respiratory syndrome outbreak. Epidemiol Health. 2015;37:e2015049. https://doi.org/10.4178/epih/e2015049

42. Figueira-Mansur J, Aguilera EA, Stoque RM, Ventura GT, Mohana-Borges R. Mutations in the dimer interfaces of the dengue virus capsid protein affect structural stability and impair RNA-capsid interaction. Sci Rep. 2019;9:2829. https:/ / doi.org/10.1038/s41598-019-39185-3

43. Escors D, Ortego J, Laude H, Enjuanes L. The membrane M protein carboxy terminus binds to transmissible gastroenteritis coronavirus core and contributes to core stability. J Virol. 2001;75:1312-24. https://doi.org/10.1128/ JVI.75.3.1312-1324.2001

44. Lee KH, Miller CR, Nagel AC, Wichman HA, Joyce P, Ytreberg FM. First-step mutations for adaptation at elevated temperature increase capsid stability in a virus. PLoS One. 2011;6:e25640. https://doi.org/10.1371/ journal.pone.0025640

45. Schuit M, Ratnesar-Shumate S, Yolitz J, Williams G, Weaver W, Green B, et al. Airborne SARS-CoV-2 is rapidly inactivated by simulated sunlight. J Infect Dis. 2020;222:56471. https://doi.org/10.1093/infdis/jiaa334

46. Matson MJ, Yinda CK, Seifert SN, Bushmaker T, Fischer RJ, van Doremalen N, et al. Effect of environmental conditions on SARS-CoV-2 stability in human nasal mucus and sputum. Emerg Infect Dis. 2020;26:26. https://doi.org/10.3201/ eid2609.202267

47. Alharbi NK, Padron-Regalado E, Thompson CP, Kupke A, Wells D, Sloan MA, et al. ChAdOx1 and MVA based vaccine candidates against MERS-CoV elicit neutralising antibodies and cellular immune responses in mice. Vaccine. 2017;35:37808. https://doi.org/10.1016/j.vaccine.2017.05.032

Address for correspondence: Michael Letko, Paul G. Allen School of Global Animal Health, Washington State University Pullman, WA 99164, USA; email: michael.letko@wsu.edu; or Vincent J. Munster, Rocky Mountain Laboratories, National Institute of Allergy and Infectious Diseases, National Institutes of Health, 903S 4th St, Hamilton, MT 59840, USA; email: vincent.munster@nih.gov 